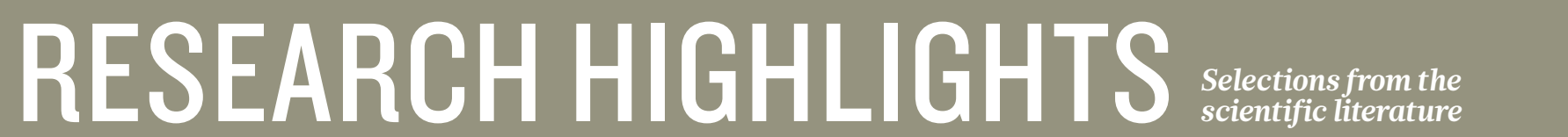

CHEMISTRY

\section{Micromotors detox chemical weapons}

Synthetic micromotors might provide a faster, better way to decontaminate nerve agents.

Converting harmful organophosphate chemicals, such as sarin, into innocuous substances requires high concentrations of hydrogen peroxide and constant stirring over long periods. Such conditions are challenging when eliminating chemicalweapons stockpiles in remote or hostile locations.

Joseph Wang at the University of California, San Diego, and his team overcame these requirements using micromotors made of polymers tipped with platinum. These zip around the contaminated fluid, propelled by bubbles that are produced as platinum reacts with peroxide. In small-volume lab tests, this micromixing neutralized nerve agents at low peroxide concentrations and without external stirring.

Two out of three nerve agents tested with micromotors were almost completely detoxified within 40 minutes. The strategy could provide a general method to accelerate reactions, the authors say.

Angew. Chem. Int. Ed. http://doi.org/f2ndgr (2013)

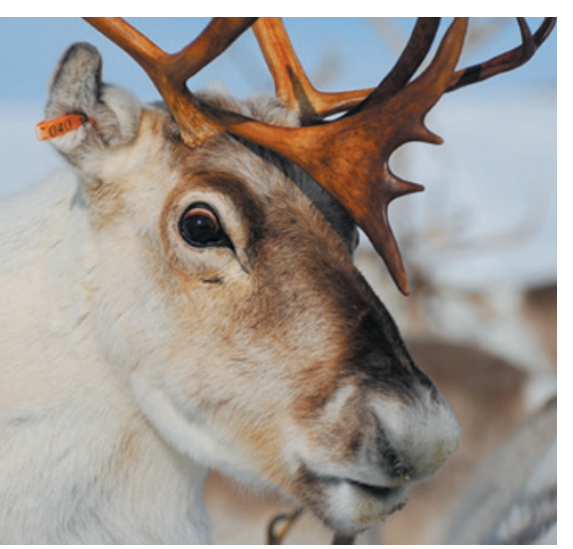

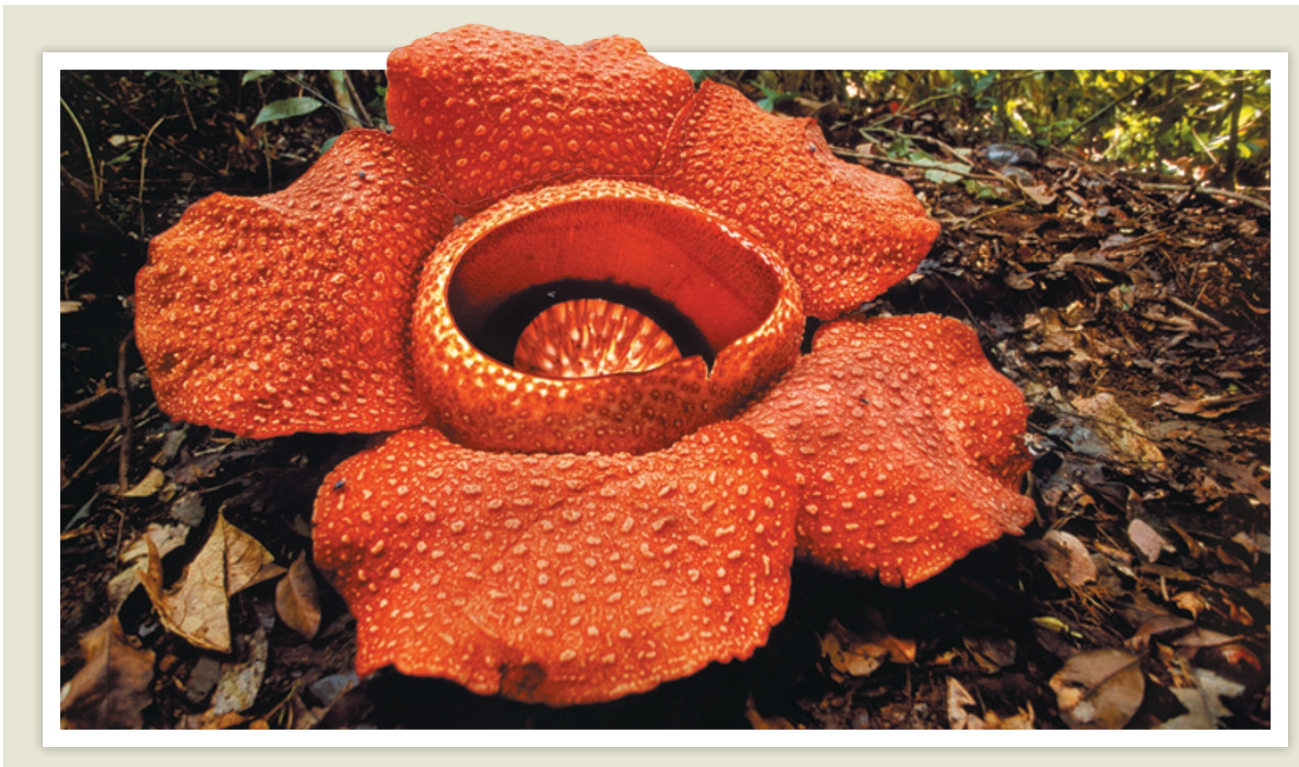

BOTANY

\section{Two routes to huge blooms}

The world's largest flowers develop in two distinct ways.

The plants Rafflesia and Sapria are two groups within the same family (Rafflesia keithii pictured). Their gigantic flowers look similar, smell like rotting meat and form large chambers to lure carrion flies as pollinators.

But when researchers led by Charles Davis of Harvard University in Cambridge, Massachusetts, examined gene-expression patterns and physical structures of developing flowers, they found that the chambers of the two plant groups come from different tissues. This suggests that the groups evolved their most characteristic features independently.

The study might also help to explain how the flowers of some Rafflesia species can get as big as one metre across - the largest of all single blossoms - without collapsing. The flower chambers are derived from the petal whorl, which could provide structural reinforcement. Proc. Natl Acad. Sci. USA http://doi.org/pq9 (2013)

\section{ZOOLOGY}

\section{Seasonal shift for reindeer eyes}

As the seasons change, Arctic reindeer (Rangifer tarandus; pictured) alter the colours at the backs of their eyes.

In cats and some other mammals, a reflective surface called the tapetum lucidum reflects light through the retina a second time and improves sight in dim light. Glen Jeffery of University College London and his colleagues studied this structure in reindeer captured within two weeks of the summer and winter solstices.

The tapetum lucideum changed from golden in summer to deep blue in winter. The winter colour seems to scatter more light across the retina.

Proc. R. Soc. B 280, 20132451 (2013)

\section{VISION}

\section{How bees see a steady landing}

Lacking stereoscopic vision, bees have evolved another technique to ensure that they land safely.

Emily Baird of Lund
University in Sweden and her colleagues discovered that honeybees (Apis mellifera ligustica; pictured) alight safely by controlling the rate at which their landing zone expands in their field of vision. Keeping this 'optic flow' constant means that bees slow down as they near their targets.

Baird's team discovered this technique by studying bees as they landed on vertical discs with a rotating spiral pattern. Optical illusions that slowed down or sped up the apparent optic flow caused bees to change their flight speeds accordingly. Rather than landing, many bees would 